\title{
Vulnerabilities in workplace features for essential workers with breast cancer: Implications for the COVID-19 pandemic
}

\author{
Madelyn Klugman ${ }^{\mathrm{a}, *}$, Sujata Patil ${ }^{\mathrm{b}, \mathrm{c}, \mathrm{d}}$, Francesca Gany ${ }^{\mathrm{c}}$ and Victoria Blinder ${ }^{\mathrm{c}, \mathrm{d}}$ \\ ${ }^{a}$ Department of Medicine, New York-Presbyterian Weill Cornell Medical Center, New York, NY, USA \\ ${ }^{\mathrm{b}}$ Department of Quantitative Health Sciences, Cleveland Clinic, Cleveland, OH, USA \\ ${ }^{\mathrm{c}}$ Department of Psychiatry and Behavioral Sciences, Memorial Sloan Kettering Cancer Center, New York, \\ $N Y, U S A$ \\ ${ }^{\mathrm{d}}$ Department of Medicine, Memorial Sloan Kettering Cancer Center, New York, NY, USA
}

Received 10 August 2021

Accepted 4 October 2021

\begin{abstract}
.
BACKGROUND: The coronavirus pandemic has highlighted the health and financial vulnerabilities of essential workers, especially among women.

OBJECTIVE: The purpose of this study is to understand the workplace environment of essential workers.

METHODS: We used data from a prospective cohort study of disparities in employment outcomes among women undergoing breast cancer treatment between 2010-2018 in New York City. We characterized participants as essential or non-essential based on self-reported occupation/industry and New York State executive orders issued during the pandemic. We compared job benefits and perceptions of workplace environment between groups.

RESULTS: There were 563 participants: 341 essential and 222 non-essential workers. Essential workers less frequently reported access to disability pay through work [n(\%): $148(58)$ versus $130(73), p<0.01]$. Essential workers in unions had greater availability of sick leave and disability pay than non-unionized essential workers ( $86 \%$ versus $53 \%, p<0.01$, and $76 \%$ versus $46 \%, p<0.01$, respectively). Health insurance differed by essential worker status $(p<0.01)$ : essential workers more frequently had public insurance (29\% versus 18\%). Surprisingly, in multivariable analyses controlling for age, race/ethnicity, income, education, chemotherapy receipt, and comfort with English, essential workers were less likely to say their employer had treated them unfairly $(p<0.01)$. However, minorities were less likely to say their employer was accommodating $(p=0.03)$ and more likely to say their employer had treated them unfairly $(p<0.01)$ than Non-Latina Whites.

CONCLUSIONS: We identified vulnerabilities in workplace protections, particularly among essential workers not in unions. Minority women more often had negative perceptions of their work environment, possibly reflecting employer bias.
\end{abstract}

Keywords: Employment, frontline, benefits, disability, union, SARS-CoV-2, coronavirus

\section{Introduction}

The workplace has changed tremendously across the globe in response to the severe acute respiratory

*Address for correspondence: Madelyn Klugman, MD, MSc, Department of Medicine, New York-Presbyterian Weill Cornell Medical Center, New York, NY, USA. E-mail:mfk9002@nyp.org. syndrome coronavirus 2 (SARS-CoV-2) pandemic. Prior to the pandemic, about $20 \%$ of employed adults reported working from home "all or most of the time," whereas in October 2020, $71 \%$ were working from home [1]. However, there are racial/ethnic, class, and gender divides between workers who can and cannot work from home. Lower- and middle-income workers [1], as well as Black and Hispanic workers, are 
less likely to be able to work from home, which has been demonstrated both prior to and during the current pandemic [1-3]. Furthermore, women comprise the majority of essential workers [4].

Frontline workers have recently come to the forefront due to the nature of the pandemic and global lockdowns. However, the workplace characteristics of frontline workers have not been well described. Understanding the experiences of these workers may provide opportunities to guide legislative action regarding protections for employees who are ill, whether due to an acute disease such as SARS-CoV2 or a chronic condition. Workplace protections are particularly important for essential workers, who are at high risk for severe SARS-CoV-2 infection given high prevalence of underlying medical conditions in that group $[5,6]$ as well as social vulnerability related to income and race/ethnicity $[7,8]$.

The purpose of this study was to compare the job characteristics (job benefits and employee perceptions of the work environment) between essential and non-essential workers in New York City to identify possible vulnerabilities in the workplace that should be addressed moving forward. We defined essential workers as those working in jobs that cannot be done remotely in essential businesses, in keeping with the executive order issued by Governor Cuomo on March 7, 2020 [9]. We used a diverse sample of women in New York City with newly diagnosed breast cancer, a diagnosis that often requires communication with employers regarding job flexibility [10]. This prospectively collected dataset allowed us to characterize the workplace of a diverse group of potentially vulnerable female employees, as minority women with breast cancer have lower rates of returning to work than non-Latina white women [11]. We hypothesized that essential workers would less frequently have access to employee protections such as disability pay and sick leave and that they would report worse subjective workplace and employer experiences. We also sought to explore the demographic and clinical factors related to these subjective experiences.

\section{Methods}

\subsection{Data source and study population}

Our study population is from the Breast Cancer and the Workforce study, a prospective cohort study of disparities in employment outcomes among women undergoing treatment for stage I-III breast cancer in New York City. This cohort has been described previously $[12,13]$. Women were recruited between October 2010 and August 2018 from two community cancer clinics, a county hospital, a community hospital, and from a National Cancer Institute-Designated Comprehensive Cancer Center. Women from racial and ethnic minority and immigrant groups were oversampled. The Institutional Review Boards at all recruitment sites approved this study, and all participants provided informed consent.

Eligible patients were women aged 18-65 able to provide consent in English, Chinese (Cantonese or Mandarin), Korean, or Spanish who were undergoing active treatment for stage I-III breast cancer and working for pay prior to diagnosis. Active therapy was defined as currently undergoing chemotherapy, radiation therapy, or having completed definitive breast cancer surgery within 60 days of enrollment. Participants completed two surveys online or in a computer-associated telephone interview, based on their preference. The first survey was completed within 2 weeks of enrollment and the follow-up survey approximately 4 months after completion of the last treatment. Unless otherwise noted, analyses in this study were sourced from the baseline survey.

\subsection{Measures and outcomes}

Essential workers were defined based on New York State's Executive Order 202.6 as well as the accompanying document, "Guidance for Determining Whether a Business Enterprise is Subject to Workforce Reduction under Recent Executive Orders," which described the set of essential businesses that were exempt from mandatory in-person workplace reductions $[9,14]$. For our analysis, any participant whose description of the job she had at the time of breast cancer diagnosis met the criteria used in the New York State guidance documents was considered an essential worker. This group included those who worked for an essential business that required in-person attendance, those who worked in-person jobs in exempt businesses documented in the guidance (i.e., state and local governments, including municipalities, authorities, and school districts), and those who provided essential services (e.g., cleaning, security, maintenance), regardless of if they worked for an essential business. 


\subsubsection{Determining essential worker status from our survey data}

Unless specifically noted below, all the data used in our study were self-reported by study participants. All study materials were translated and pilot tested as described previously $[12,15]$. To determine essential worker status, participant answers to two open-ended questions ("What's your job title?" and "What kind of work do you do?") and to two multiple-choice questions regarding job category and industry were manually coded using the 2018 version of the Standard Occupational Classification system of the Bureau of Labor Statistics (SOC) [16]. Two participants did not provide enough information to determine an SOC classification and were excluded from this analysis. If the SOC category alone was insufficient to determine essential worker status, participants' responses to questions about employer size, self-employed status, and whether or not they supervised others were also used. If we were unable to rule out that a participant was an essential worker (e.g., works as a cashier, but unclear if the business is an essential one), they were assumed to be an essential worker.

\subsubsection{Other variables from survey instrument}

Demographic and other individual variables in our study included age, race or ethnicity, level of comfort speaking English (for those who spoke a different language as children), education, individual income, and health insurance. Health insurance was categorized into private insurance provided through the participant's job, other private insurance (e.g., provided through a spouse's job), and publicly-provided insurance (e.g., Medicaid, Emergency Medicaid, or Medicare). Additional job-related data captured in the surveys included employer size, part-time worker status, and union status (the latter based on the question: "Are you a member of a labor union?"). Availability of disability pay and sick leave benefits was ascertained in post-treatment surveys as it was expected that participants would have inquired further about these benefits as they underwent breast cancer treatment. Participants' perceptions about their work environment were measured by asking about how much they agreed or disagreed with statements that: 1) their work schedule was flexible, 2) their employer was good at accommodating their illness and need for treatment, 3) their employer treated them unfairly because they had cancer, and 4) they worried about being forced to retire or quit before they were ready. These responses were dichotomized such that the comparison would be between the most favorable workplace environment and all others (e.g., for the statement "My schedule at work is flexible now," the responses were coded as "strongly agree" vs. all other responses: "somewhat agree," "neither agree nor disagree," "somewhat disagree," and "strongly disagree"). Perceptions about the work environment were ascertained in the follow-up survey, with the expectation that, after treatment completion, workers would have a better understanding of the workplace environment during cancer treatment.

Clinical cancer variables included in this analysis were stage at diagnosis and whether or not chemotherapy had been administered (both chartabstracted). Comorbid medical conditions were assessed using questions from the Charlson Comorbidity Index as modified for patient report [17, 18]. However, because the sample generally had none or only one of a limited number of comorbid conditions, rather than reporting a value for the index, we report the frequencies of specific medical conditions.

\subsection{Statistical analysis}

Analyses were mainly descriptive, reflecting our goal of characterizing differences in essential vs. nonessential workers. As our analysis is a secondary analysis of data from the Breast Cancer and the Workforce study, no power calculation was performed. Differences in demographic, employment, and clinical characteristics by essential vs. non-essential workers were tested using the chi-squared test for categorical variables, and the $t$-test or Mann-Whitney $\mathrm{U}$ test for continuous variables.

We conducted additional analyses exploring the factors related to participant perceptions of their work environment by building four multivariable logistic regression models (with the four workplace perceptions as outcomes). Each model was construed such that a greater odds ratio indicated a more favorable workplace perception (i.e., more likely to strongly agree with a positive perception such as workplace flexibility or more likely to strongly disagree with a negative perception such as unfair treatment). These models were constructed by assessing the univariate associations of sociodemographic and clinical variables with the outcomes, and variables that were significant in at least one univariate analysis were considered for inclusion in the multivariable models. Ultimately, the model predictors included: essential worker status, age, race/ethnicity, annual individ- 
Table 1

Essential worker status by race/ethnicity, in a cohort of non-essential and essential workers with breast cancer

\begin{tabular}{lcccc}
\hline & $\begin{array}{c}\text { Non-essential } \\
(\mathrm{N}=222)\end{array}$ & $\begin{array}{c}\text { Essential } \\
(\mathrm{N}=341)\end{array}$ & Total & $\begin{array}{c}p \text {-value } \\
<0.01\end{array}$ \\
Race/ethnicity ${ }^{1}$ & $\mathrm{~N}(\%)$ & $\mathrm{N}(\%)$ & & \\
\hline Hispanic or Latina & $42(27)$ & $113(73)$ & 155 & \\
Black or African & $40(31)$ & $89(69)$ & 129 & \\
$\quad$ American & & & & \\
Chinese & $59(50)$ & $58(50)$ & 117 & \\
Non-latina white & $52(52)$ & $48(48)$ & 100 & \\
Korean & $23(61)$ & $15(39)$ & 38 & \\
Other & $4(27)$ & $11(73)$ & 15 & \\
Unknown & 2 & 7 & 9 & \\
\hline
\end{tabular}

${ }^{1}$ Row percentages are provided.

ual income, education, receipt of chemotherapy, and comfort with speaking English.

All analyses were conducted in SAS v9 and R v3.6. All $p$-values are two-sided, and $p$-values $<0.05$ are considered statistically significant.

\section{Results}

Of 563 participants in the sample, $476(85 \%)$ completed follow-up surveys four months after completion of breast cancer treatment. There was no difference in essential worker status between those who did or did not complete a follow-up survey. However, participants who were lost to follow-up more frequently identified as Black or African-American (33 vs. $22 \%$ of those with a follow-up survey) and more likely to report an individual income of $<50 \mathrm{~K}$ annually (63 vs. 53\%).

Overall, 341 participants $(61 \%)$ were characterized as essential workers (Table 1). The self-reported racial/ethnic composition of the entire sample was the following: Hispanic or Latina [n(\%): 155 (28)], Black or African American [129 (23)], Chinese [117 (21\%)], non-Latina white [100 (18)], Korean [38 (7)], and Other [15(3)]. The majority of Hispanic or Latina, Black or African American, and Chinese participants were classified as essential workers.

Among essential workers, the most common SOC categories were "home health aides" (11\% of essential workers), "childcare workers" (5\%), and "registered nurses" (4\%) (data not shown). Among non-essential workers, the most frequent SOC designations were "financial managers" (5\% of non-essential workers), "accountants and auditors" (5\%), and "financial and investment analysts" (4\%).

Essential workers were slightly older [mean (standard deviation) 51 (8) vs. 49 (9)], had higher rates
Table 2

Demographic and clinical features of non-essential and essential workers with breast cancer

\begin{tabular}{lccc}
\hline & $\begin{array}{c}\text { Non-essential } \\
(\mathrm{N}=222) \\
\mathrm{N}(\%)\end{array}$ & $\begin{array}{c}\text { Essential } \\
(\mathrm{N}=341)\end{array}$ & $p$-value \\
& $\mathrm{N}(\%)$ & \\
\hline Age (years) & $49(9)$ & $51(8)$ & $<0.01$ \\
Year of diagnosis & & & 0.66 \\
$\quad 2009-2013$ & $46(22)$ & $78(24)$ & \\
$\quad$ 2014-2018 & $162(78)$ & $245(76)$ & \\
Stage of cancer presentation & & & 0.16 \\
$\quad 1$ & $83(39)$ & $126(38)$ & \\
2 & $104(49)$ & $145(44)$ & \\
3 & $25(12)$ & $59(18)$ & \\
Hypertension & & & 0.04 \\
$\quad$ No & $178(82)$ & $243(74)$ & \\
$\quad$ Yes & $40(18)$ & $87(26)$ & \\
Diabetes & & & 0.02 \\
$\quad$ No & $207(94)$ & $289(88)$ & \\
$\quad$ Yes & $13(6)$ & $41(12)$ & \\
Education & & & 0.02 \\
$\quad<$ HS & $10(5)$ & $36(11)$ & \\
$\quad$ HS or more & $209(95)$ & $299(89)$ & \\
Annual job income & & & $<0.01$ \\
$\quad<50 k$ & $79(36)$ & $222(66)$ & \\
$\quad>100 \mathrm{k}$ & $66(30)$ & $37(11)$ & \\
50-100K & $75(24)$ & $77(23)$ & \\
\hline
\end{tabular}

${ }^{1}$ Mean (standard deviation).

of hypertension ( 26 vs. $18 \%, p=0.04$ ) and higher rates of diabetes mellitus (12 vs. $6 \%, p=0.02)$ than non-essential workers (Table 2). Essential workers had lower educational attainment $(p=0.02)$ and lower individual income $(p<0.01)$. No differences in essential vs non-essential worker status were observed in year of diagnosis nor stage of cancer presentation.

Workplace features by essential vs. non-essential status are listed in Table 3. Most essential and nonessential workers reported working full time at their jobs (83 and $89 \%$, respectively). Likewise, no difference was observed in employer size. However, essential workers were significantly $(p<0.01)$ less likely than non-essential workers to have health insurance provided through their employers (51 versus $64 \%$ ) and more likely to be publicly insured (29 versus $18 \%)$. Essential workers were also more likely to be part of a union ( $37 \%$ vs $13 \%, p<0.01)$. Posttreatment, essential workers were less likely than non-essential workers to report that the job they had at the time of their diagnosis offered disability pay (58 versus $73 \%, p<0.01)$. Though not statistically significant, a numerical difference was observed in the availability of sick leave (65\% of essential vs. $73 \%$ of non-essential workers, $p=0.10$ ). In an exploratory stratified analysis, unionized essential workers were much more likely to have access to disability pay and 
Table 3

Workplace features of non-essential and essential workers with breast cancer

\begin{tabular}{|c|c|c|c|}
\hline & $\begin{array}{c}\text { Non-essential } \\
\begin{array}{c}(\mathrm{N}=222) \\
\mathrm{N}(\%)\end{array}\end{array}$ & $\begin{array}{c}\text { Essential } \\
(\mathrm{N}=341) \\
\mathrm{N}(\%)\end{array}$ & $p$-value \\
\hline \multicolumn{3}{|l|}{ Employer size } & 0.38 \\
\hline$<15$ & $27(14)$ & $53(18)$ & \\
\hline $15-49$ & $12(6)$ & $27(9)$ & \\
\hline $50-99$ & $10(5)$ & $13(5)$ & \\
\hline 100 or more & $139(74)$ & $196(68)$ & \\
\hline Unknown & 34 & 52 & \\
\hline \multicolumn{3}{|l|}{ Full time worker } & 0.10 \\
\hline No & $25(11)$ & $56(17)$ & \\
\hline Yes & $195(89)$ & $277(83)$ & \\
\hline \multicolumn{3}{|l|}{ Union } & $<0.01$ \\
\hline No & $194(87)$ & $211(63)$ & \\
\hline Yes & $28(13)$ & $124(37)$ & \\
\hline \multicolumn{4}{|l|}{ Benefits } \\
\hline \multicolumn{3}{|l|}{$\overline{\text { Insurance }}$} & $<0.01$ \\
\hline Public & $37(18)$ & $92(29)$ & \\
\hline Employer & $136(64)$ & $161(51)$ & \\
\hline Non employer private & $38(18)$ & $64(20)$ & \\
\hline \multicolumn{3}{|l|}{ Sick leave $^{1}$} & 0.10 \\
\hline No & $48(27)$ & $92(35)$ & \\
\hline Yes & $131(73)$ & $174(65)$ & \\
\hline Unknown & 43 & 75 & \\
\hline \multicolumn{3}{|l|}{ Disability pay ${ }^{1}$} & $<0.01$ \\
\hline No & $48(27)$ & $109(42)$ & \\
\hline Yes & $130(73)$ & $148(58)$ & \\
\hline Unknown & 44 & 84 & \\
\hline \multicolumn{4}{|c|}{ Negative perceptions $^{1}$} \\
\hline \multicolumn{3}{|c|}{$\begin{array}{l}\text { Worry about being forced to retire } \\
\text { or quit before ready }\end{array}$} & 0.06 \\
\hline Strongly disagree & $99(53)$ & $120(44)$ & \\
\hline All other options ${ }^{2}$ & $88(47)$ & $155(56)$ & \\
\hline Unknown & 35 & 66 & \\
\hline \multicolumn{3}{|c|}{ Employer treats unfairly because I have cancer } & 0.07 \\
\hline Strongly disagree & $119(63)$ & $196(72)$ & \\
\hline All other options & $69(37)$ & $77(28)$ & \\
\hline Unknown & 34 & 68 & \\
\hline \multicolumn{4}{|l|}{ Positive perceptions $^{1}$} \\
\hline \multicolumn{3}{|l|}{ Work schedule is flexible } & $>0.99$ \\
\hline Strongly agree & $61(32)$ & $120(44)$ & \\
\hline All other options & $127(68)$ & $155(56)$ & \\
\hline Unknown & 34 & 66 & \\
\hline \multicolumn{3}{|c|}{$\begin{array}{l}\text { Employer is good at accommodating } \\
\text { illness and need for treatment }\end{array}$} & $>0.99$ \\
\hline Strongly agree & $109(58)$ & $159(58)$ & \\
\hline All other options & $79(42)$ & $115(42)$ & \\
\hline Unknown & 34 & 67 & \\
\hline
\end{tabular}

${ }^{1}$ Obtained approximately 4 months after completion of the last breast cancer treatment. Each variable has $<5 \%$ unknown data unless otherwise noted. ${ }^{2}$ Participant selected any of the other four options on the Likert scale (the five options were strongly disagree, disagree, neither agree or disagree, agree, strongly agree).

sick leave benefits than nonunionized essential workers [n (\%): disability pay: 78 (76) versus 70 (46), $p<0.01$; sick leave: 88 (86) vs $86(53), p<0.01$; data not shown].
No statistically significant differences were found, based on essential vs. non-essential worker status, in participants' perceptions of their workplace environment after treatment completion. (Table 3). Of note, fewer than half of participants of both groups strongly agreed that their job offered schedule flexibility.

In an exploratory multivariable analysis assessing predictors of participants' perceptions of their workplace environment (Table 4), essential workers were more likely to report that their employer had been good at accommodating their needs during cancer treatment, though this finding was not statistically significant [odds ratio, $95 \%$ confidence interval (OR, 95\% CI): 1.55 (1.00-2.44)]. Essential workers were also more than twice as likely to strongly disagree that their employer had treated them unfairly because they had cancer [OR, 95\% CI: 2.05 (1.28-3.32)]. Generally, older workers had less favorable perceptions than younger workers with respect to the employers' having been accommodating and treated them unfairly. Race/ethnicity was also independently associated with perceptions of the work environment, with minority groups more frequently perceiving their workplaces unfavorably than NonLatina Whites. For example, Black women were 50\% less likely to report that their employer had been good at accommodating their illness and 25\% less likely to report that their work schedule was flexible. They were also $60 \%$ less likely to disagree when asked if their employer treated them unfairly (implying that they thought their employer had treated them unfairly). Annual income, education, receipt of chemotherapy, and comfort speaking English were not statistically significant in the multivariable analyses.

\section{Discussion}

\subsection{Summary of findings}

In this study, we found that within a diverse sample of women with breast cancer, essential workers were more likely to earn a lower annual income and less likely to report that their employer offered disability pay, and they were less likely to be on their employer's health plan. The majority of Black and Latina women were essential workers, highlighting the overrepresentation of minority groups in essential worker jobs. Unionized essential workers were more likely to have access to disability or sick-leave benefits than essential workers not in unions. Minority women more often had negative perceptions of their 
Table 4

Multivariable analysis of predictors of favorable workplace perceptions among workers with breast cancer

\begin{tabular}{|c|c|c|c|c|c|c|c|c|c|c|c|c|}
\hline \multicolumn{7}{|c|}{ Positive perceptions $^{1}$} & \multicolumn{6}{|c|}{ Negative perceptions $^{2}$} \\
\hline \multicolumn{4}{|c|}{$\begin{array}{c}\text { Employer good at } \\
\text { accommodating illness and } \\
\text { need for treatment }(\mathrm{N}=422)\end{array}$} & \multicolumn{3}{|c|}{$\begin{array}{l}\text { Work schedule is } \\
\text { flexible }(\mathrm{N}=423)\end{array}$} & \multicolumn{3}{|c|}{$\begin{array}{l}\text { Worry about forced } \\
\text { to retire or quit before } \\
\text { ready }(\mathrm{N}=422)\end{array}$} & \multicolumn{3}{|c|}{$\begin{array}{c}\text { Employer treats me } \\
\text { unfairly because I } \\
\text { have cancer }(\mathrm{N}=421)\end{array}$} \\
\hline Characteristic & OR & $95 \% \mathrm{CI}$ & $\begin{array}{c}p- \\
\text { value }\end{array}$ & OR & $95 \% \mathrm{CI}$ & $\begin{array}{c}p- \\
\text { value }\end{array}$ & $\overline{\mathrm{OR}}$ & $95 \%$ CI & $\begin{array}{c}p- \\
\text { value }\end{array}$ & $\overline{\mathrm{OR}}$ & $95 \% \mathrm{CI}$ & $\begin{array}{c}p- \\
\text { value }\end{array}$ \\
\hline Essential worker & & & 0.05 & & & 0.7 & & & 0.6 & & & $<0.01 *$ \\
\hline No & 1 & ref & & 1 & ref & & 1 & ref & & 1 & ref & \\
\hline Yes & 1.55 & $1.00,2.44$ & & 0.93 & $0.61,1.43$ & & 0.88 & $0.55,1.39$ & & 2.05 & $1.28,3.32$ & \\
\hline Age & 0.98 & $0.95,1.00$ & $0.05 *$ & 0.98 & $0.96,1.01$ & 0.2 & 0.98 & $0.96,1.01$ & 0.2 & 0.97 & $0.95,1.00$ & $0.04 *$ \\
\hline Race/ethnicity & & & $0.03 *$ & & & 0.06 & & & $0.02 *$ & & & $<0.01^{*}$ \\
\hline Non-latina white & 1 & ref & & 1 & ref & & 1 & ref & & 1 & ref & \\
\hline Black or African-American & 0.50 & $0.26,0.93$ & & 0.75 & $0.41,1.34$ & & 0.97 & $0.52,1.82$ & & 0.40 & $0.19,0.79$ & \\
\hline Chinese & 0.43 & $0.22,0.81$ & & 0.53 & $0.29,0.98$ & & 0.58 & $0.29,1.14$ & & 0.24 & $0.11,0.48$ & \\
\hline Korean & 1.04 & $0.41,2.78$ & & 1.05 & $0.44,2.57$ & & 0.75 & $0.28,1.87$ & & 0.33 & $0.13,0.86$ & \\
\hline Hispanic or Latina & 0.78 & $0.40,1.52$ & & 0.45 & $0.24,0.85$ & & 1.75 & $0.92,3.36$ & & 0.78 & $0.36,1.66$ & \\
\hline Annual income & & & 0.1 & & & 0.7 & & & $>0.9$ & & & 0.3 \\
\hline$<50 \mathrm{k}$ & 1 & ref & & 1 & ref & & 1 & ref & & 1 & ref & \\
\hline$>100 \mathrm{k}$ & 1.87 & $1.04,3.42$ & & 1.18 & $0.68,2.06$ & & 0.97 & $0.53,1.76$ & & 1.61 & $0.87,3.04$ & \\
\hline $50-100 \mathrm{~K}$ & 1.21 & $0.73,2.01$ & & 1.19 & $0.73,1.95$ & & 0.91 & $0.54,1.54$ & & 1.4 & $0.82,2.44$ & \\
\hline Education & & & 0.1 & & & 0.8 & & & 0.1 & & & 0.8 \\
\hline$<\mathrm{HS}$ & 1 & ref & & 1 & ref & & 1 & ref & & 1 & ref & \\
\hline HS or more & 2.05 & $0.87,5.05$ & & 1.12 & $0.47,2.81$ & & 2.14 & $0.86,5.90$ & & 0.88 & $0.34,2.16$ & \\
\hline Chemotherapy & & & 0.4 & & & 0.8 & & & 0.05 & & & $>0.9$ \\
\hline No & 1 & ref & & 1 & ref & & 1 & ref & & 1 & ref & \\
\hline Yes & 1.29 & $0.71,2.33$ & & 1.08 & $0.60,1.96$ & & 1.94 & $1.00,4.04$ & & 1.03 & $0.53,1.93$ & \\
\hline Comfort with English & & & 0.09 & & & 0.2 & & & 0.5 & & & 0.3 \\
\hline No & 1 & ref & & 1 & ref & & 1 & ref & & 1 & ref & \\
\hline Yes & 1.75 & $0.92,3.37$ & & 1.62 & $0.84,3.21$ & & 0.78 & $0.40,1.54$ & & 1.45 & $0.73,2.89$ & \\
\hline
\end{tabular}

$\mathrm{OR}=$ Odds Ratio, $\mathrm{CI}=$ Confidence Interval. Values with an asterixis $(*)$ are statistically significant $(p<0.05) .{ }^{1}$ For positive perceptions, an $\mathrm{OR}>1$ suggests a favorable perception (more likely to agree with statement). ${ }^{2}$ For negative perceptions, an OR $>1$ suggests a favorable perception (more likely to disagree with statement).

work environment. Our paper demonstrates an economic vulnerability among essential workers, which could be exacerbated by an acute illness, such as COVID-19.

\subsection{Potential explanation and implications of lower job benefits in essential workers}

Low-income workers in the US more frequently work in smaller settings that are not covered under the federal Americans with Disabilities Act, which applies only to businesses with at least 15 employees $[12,19]$. Furthermore, low-income workers are less likely to have access to paid sick leave [20]. Thus, the finding that essential workers in our study earned a lower annual income than non-essential workers may, in part, explain why essential workers less frequently reported having access to job benefits. A notable exception was the group of essential workers who belonged to unions, who more frequently reported access to sick leave and disability pay at work. These employees may have better awareness of benefits due to the union's organization and communication with its members, higher levels of benefits due to collective bargaining, or both. Employees who are not unionized may require legislative action to obtain similar levels of benefits, as has been highlighted by the pandemic, which exposed important vulnerabilities in workplace protections for essential workers, particularly for women [21]. Women, who were exclusively studied in this report, have faced substantial burdens related to the COVID-19 pandemic, including but not limited to difficulties fulfilling work obligations due to school closures, new caregiving responsibilities for family members, and mental health issues due to the stress and worry of the pandemic [22]. In response to deficiencies in workplace protections, in April 2020, New York State enacted legislation for a sick leave law that provides most employees up to 5 days of paid sick leave [23]. This is clearly a good start, but for patients undergoing several months of chemotherapy requiring multiple visits for treatment administration, or for those requiring treatment (and quarantining) for COVID-19, it is not sufficient. 


\subsection{Potential explanations of essential workers' more favorable views of their employer}

Surprisingly, in light of their decreased access to employer benefits, essential workers had more favorable views on whether or not their employer had been accommodating or treated them unfairly, after controlling for demographic characteristics and receipt of chemotherapy. It is possible that, because essential workers in our analysis were more closely clustered in specific job types (e.g., 11\% were home health aides), there may have been more homogeneity in expectations and contracts compared to non-essential workers employed in unique fields.

However, in light of the significant differences demonstrated in the perceived work environment based on race and ethnicity and (to a lesser extent) on age, it may also be that access to an accommodating work environment (and unfair treatment at work) is based on the employer's relationship or interaction with the worker and is, therefore, more subject to bias, with non-white and older workers having less access to accommodations as a result. Previous studies have shown that racial and ethnic minorities, and workers who are older, are less likely to receive workplace accommodations or work in supportive work environments $[24,25]$. Workplace protections may be particularly important for these vulnerable groups, and standardization and clear communication of types of accommodations that may (and should) be provided may be important to limit further workplace and healthcare disparities.

\subsection{Strengths and limitations}

The strengths of this study include its highly diverse sample, with high proportions of racial and ethnic minorities and immigrant groups. In addition, we were able to classify workers as essential or nonessential based on their responses to several survey questions, including a free text of the job description. Furthermore, we were able to apply New York State guidance to categorize these workers, which is important given the state-level differences in essential worker classifications. Other studies have utilized different methods of determining essential worker status based on federal guidance $[6,26]$; however, they focus on workers in critical infrastructures (regardless of whether or not they can work in person or remote), whereas our study focused on vulnerable workers who were unable to work remotely. Our approach highlights the importance of defining who is considered an essential worker and including whether or not the job may be performed remotely in the definition.

\section{Conclusion}

Our study has several limitations, particularly regarding generalizability and loss to follow-up. Our sample from New York City medical centers primarily reflect the experience of New York City workers, who work in a state with strong worker protections relative to the rest of the country [27]. Therefore, our findings may not be as applicable to essential and non-essential workers in other geographic regions. Furthermore, the data analyzed in our study were collected prior to the pandemic and may not reflect the current employment environment and attitudes, particularly for non-essential workers who may report more workplace flexibility as more workers transition to remote work. A qualitative study of breast cancer survivors noted that many employees felt that they could work from home more frequently if they were provided the technology and other resources supplied by their jobs [10]. In addition, because patients with a new cancer diagnosis may enroll in Emergency Medicaid, patients in our study were virtually all insured at the time of enrollment and may not reflect the workplace experiences of essential workers who are medically uninsured. A limitation of data used from our follow-up survey (sick leave and disability benefits and perceptions of work environment) is that there were missing data due to participant drop-out (15\%). However, we felt these results were better representative of the participants' workplace benefits compared to the baseline assessments, as participants had more time to understand the full extent of their workplace benefits and interactions with the employer after completion of treatment.

\section{Acknowledgments}

This work was supported by the American Cancer Society (MRSGT-11-002-01-CPHPS), American Society of Clinical Oncology (career development award), National Cancer Institute (R37 CA214785), City College of New York/Memorial Sloan Kettering Cancer Center Partnership for Cancer Research Training and Community Outreach (U54 CA137788), and Department of Health 
and Human Services (Cancer Center Support grant P30 CA 008748, Memorial Sloan Kettering Cancer Center).

\section{Conflicts of interest}

Victoria Blinder has been a consultant for Workplace Transitions for People Touched by Cancer, an online publicly available tool kit for employers seeking to accommodate cancer patients and their caregivers at work. Funding for the tool kit's development and evaluation (including salary support for Dr. Blinder) was been provided by the Anthem Foundation and Pfizer. Sujata Patil consults with ByHeart. Madelyn Klugman and Francesca Gany have no conflicts of interest to declare.

\section{References}

[1] Parker K, Horowitz, J. and Minkin, R.. How the Coronavirus Outbreak Has - and Hasn't - Changed the Way Americans Work: Pew Research Center; 2020 [Available from: https://www.pewresearch.org/socialtrends/2020/12/09/how-the-coronavirus-outbreak-has-andhasnt-changed-the-way-americans-work/ Accessed March $1,2021$.

[2] Table 1. Workers who could work at home, did work at home, and were paid for work at home, by selected characteristics, averages for the period 2017-2018: U.S. Bureau of Labor Statistics; 2019 [Available from: https://www.bls.gov/news.release/flex2.t01.htm Accessed April 15, 2021.

[3] Selden TM, Berdahl TA. COVID-19 And Racial/Ethnic Disparities In Health Risk, Employment, And Household Composition. Health Aff (Millwood). 2020;39(9):1624-32.

[4] Gebeloff CRaR. When It Comes to 'Essential,' It's a Woman's World Today. The New York Times. 2020 April 19;Sect. A. Accessed April 15, 2021.

[5] Silver SR, Li J, Boal WL, Shockey TL, Groenewold MR. Prevalence of Underlying Medical Conditions Among Selected Essential Critical Infrastructure Workers - Behavioral Risk Factor Surveillance System, 31 States, 2017-2018. MMWR Morb Mortal Wkly Rep. 2020;69(36):1244-9.

[6] Selden TM, Berdahl TA. Risk of Severe COVID-19 Among Workers and Their Household Members. JAMA Intern Med. 2021;181(1):120-2.

[7] Kim SJ, Bostwick W. Social Vulnerability and Racial Inequality in COVID-19 Deaths in Chicago. Health Educ Behav. 2020;47(4):509-13.

[8] Paremoer L, Nandi S, Serag H, Baum F. Covid-19 pandemic and the social determinants of health. BMJ. 2021;372:n129.

[9] Guidance for determining whether a business enterprise is subject to a workforce reduction under recent executive orders: New York State Department of Economic Development; 2020 [updated October 23, 2020. Avail- able from: https://esd.ny.gov/guidance-executive-order2026 Accessed November 22, 2020.

[10] Sun W, Chen K, Terhaar A, Wiegmann DA, Heidrich SM, Tevaarwerk AJ, et al. Work-related barriers, facilitators, and strategies of breast cancer survivors working during curative treatment. Work. 2016;55(4):783-95.

[11] Cocchiara RA, Sciarra I, D'Egidio V, Sestili C, Mancino M, Backhaus I, et al. Returning to work after breast cancer: A systematic review of reviews. Work. 2018;61(3):463-76.

[12] Blinder V, Eberle C, Patil S, Gany FM, Bradley CJ. Women With Breast Cancer Who Work For Accommodating Employers More Likely To Retain Jobs After Treatment. Health Aff (Millwood). 2017;36(2):274-81.

[13] Blinder VS, Eberle CE, Tran C, Bao T, Malik M, Jung G, et al. Use of patient-reported controls for secular trends to study disparities in cancer-related job loss. J Cancer Surviv. 2020 .

[14] No. 202.6: Continuing Temporary Suspension and Modification of Laws Relating to the Disaster Emergency Albany, NY: New York State; [Available from: https://www.gover nor.ny.gov/news/no-2026-continuing-temporary-suspension -and-modification-laws-relating-disaster-emergency Accessed November 22, 2020.

[15] Eremenco SL, Cella D, Arnold BJ. A comprehensive method for the translation and cross-cultural validation of health status questionnaires. Eval Health Prof. 2005;28(2):212-32.

[16] Standard Occupational Classification User Guide Washington, DC: U.S. Bureau of Labor Statistics; 2017 [Available from: https://www.bls.gov/soc/2018/soc_2018_user_ guide.pdf Accessed November 22, 2020.

[17] Charlson ME, Pompei P, Ales KL, MacKenzie CR. A new method of classifying prognostic comorbidity in longitudinal studies: development and validation. J Chronic Dis. 1987;40(5):373-83.

[18] Katz JN, Chang LC, Sangha O, Fossel AH, Bates DW. Can comorbidity be measured by questionnaire rather than medical record review? Med Care. 1996;34(1):73-84.

[19] Shartzer A, Blavin F, Holahan J. Employer-Sponsored Insurance Stable For Low-Income Workers In Medicaid Expansion States. Health Aff (Millwood). 2018;37(4):60712.

[20] Hall GS, Walters S, Wimer C, Levanon Seligson A, Maury M, Waldfogel J, et al. Workers not Paid for Sick Leave after Implementation of the New York City Paid Sick Leave Law. J Urban Health. 2018;95(1):134-40.

[21] Ghilarducci T, Farmand A. Older Workers on the COVID19-Frontlines without Paid Sick Leave. J Aging Soc Policy. 2020;32(4-5):471-6.

[22] Ranji U, Frederiksen, B., Salganicoff, A., Long, M. Women, Work, and Family During COVID-19: Findings from the KFF Women's Health Survey: Kaiser Family Foundation; 2021 [Available from: https://www.kff.org/womens-healthpolicy/issue-brief/women-work-and-family-during-covid19-findings-from-the-kff-womens-health-survey/ Accessed May 22, 2021.

[23] New York Paid Sick Leave: New York State; [Available from: https://www1.nyc.gov/site/dca/workers/workersrights/paid-sick-leave-law-for-workers.page Accessed March 31, 2021.

[24] Blanck P, Hyseni F, Altunkol Wise F. Diversity and Inclusion in the American Legal Profession: Workplace Accommodations for Lawyers with Disabilities and Lawyers Who Identify as LGBTQ. J Occup Rehabil. 2020;30(4):537-64. 
[25] Mujahid MS, Janz NK, Hawley ST, Griggs JJ, Hamilton AS, Graff J, et al. Racial/ethnic differences in job loss for women with breast cancer. J Cancer Surviv. 2011;5(1):102-11.

[26] Hawkins D. Differential occupational risk for COVID-19 and other infection exposure according to race and ethnicity. Am J Ind Med. 2020;63(9):817-20.

[27] Stapleton S. Best and Worst States to Work in America: OxFam America; 2019 [cited 2021 September 1]. Avail- able from: https://webassets.oxfamamerica.org/media/ documents/BSWI_2019_Report_Final.pdf?_gl=1*isq7zl*_ ga*NDQwNjg0MDk4LjE2MzA1MzU1NzI.*_ga_R58YET D6XK*MTYzMDUzNTU3MS4xLjEuMTYzMDUzNTk1 OS4w Accessed September 1, 2021. 